\title{
Mate Preferences in Young Iranian Women: Cultural and Individual Difference Correlates
}

\author{
Mohammad $\operatorname{Atari}^{1}$ (D) Ramin Jamali ${ }^{2}$
}

Published online: 23 June 2016

(C) Springer International Publishing 2016

\begin{abstract}
The present study investigated the link between long-term mate preferences and cultural and individual difference variables in 536 young Iranian women (mean age $=21.6$, $S D=3.78$ ). We tested a priori hypotheses on the relationships between the dimensions of women's mate preferences (kindness/dependability, status/resources, attractiveness/sexuality, religiosity/chastity, and education/intelligence) and other study variables (the desired number of children, selfperceived attractiveness, self-rated intelligence, intrinsic religiosity, Mahr, and socio-economic status). Descriptive data suggested that young Iranian women do not endorse traditional and religious practices in marriage and long-term relationships as strongly as previously thought. Results were mostly in line with the hypotheses. Overall, the relationships between the study variables provided support for the similarity hypothesis and the notion of modernization of Iran. Limitations and future directions are discussed.
\end{abstract}

Keywords Mate preferences $\cdot$ Culture $\cdot$ Women $\cdot$ Marriage $\cdot$ Iran

\section{Introduction}

In most mammals including humans, there are robust sex differences in the minimal amount of energy and effort necessary

Mohammad Atari

Mohammad.attari@yahoo.com; Atari@ut.ac.ir

Department of Psychology, University of Tehran, Tehran, Iran

2 Department of Psychology, Science and Research Branch, Islamic Azad University, Tehran, Iran to reproduce (Clutton-Brock 1991). In comparison, men spend much less energy to reproduce. While it might take few minutes for men to copulate to produce an offspring, women are burdened with a long gestational period of time followed by years or months of lactation to produce and rear that same offspring. Therefore, in deep evolutionary history of men and women, they faced qualitatively different problems as well as similar ones. Specifically, the most prominent barrier to men's successful reproduction was sexual access to healthy and fertile women. The most prominent evolutionarily recurrent problem for women, however, was securing a sexual partner who would provide adequate paternal support for them and their offspring (Trivers 1972). The mating psychology in modern humans is based on the deep evolutionary history of humans and adaptations in response to evolutionarily recurrent problems (Buss 1994).

According to the evolutionary theory in human mating context, women are more unwilling to sexual encounters with a stranger as compared with men (Clark and Hatfield 1989). Women also set higher standards for accepting a prospective mate and desire fewer partners in comparison with men (Simpson and Gangestad 1991). There are a number of female-specific variables that can alter women's preferences in choosing a mate (see Frederick, Reynolds, and Fisher 2013). Generally, women hold certain preferences in choosing a mate and calibrate their preferences for a potential mate based on their own characteristics and personal qualities. For example, physical attractiveness (e.g., Buss and Shackelford 2008), intelligence (e.g., Stanik and Ellsworth 2010), religiosity (e.g., Schmitt and Fuller 2015), socio-economic status (e.g., Khallad 2005), and cultural variables (e.g., Schmitt 2005) can impact women's long-term mate preferences and mating strategies.

Scientific investigation of long-term mate preferences provides insight into cultural values. That is, within- 
culture examination of mate preferences can determine what people of that culture consider desirable or, on the other hand, socially unacceptable. Long-term mate preferences can highlight the cultural traditions and social values. In addition, changes in mate preferences can determine extant cultural values and new alterations in what people want in a potential mate (Chang, Wang, Shackelford, and Buss 2011; Kamble, Shackelford, Pham, and Buss 2014; Souza, Conroy-Beam, and Buss 2016). The scientific study of short-term and long-term mate preferences across cultures represents an important ongoing scientific endeavor (e.g., Schmitt 2005; Schmitt and Jonason 2014). However, little is known about women's mate preferences and their associations with culture-specific variables, especially in non-Western cultures.

While women's long-term mate preferences have been examined within several non-Western cultures (e.g., Kamble et al. 2014; Souza et al. 2016), they have not been well-researched in Iranian context. Furthermore, the associations between culture-specific variables and longterm mate preferences have not been empirically tested in Iranian context. Iran may be considered an interesting cultural context for studying human mating psychology due to the historic incidents and cultural alterations. Iran may also be considered heir to one of the oldest civilizations (Huyse 1998; Yarshater 2013). Since the Achaemenid Empire (550 BC), different kingdoms have ruled in Iran (previously known as Persia). The religion of Persians was Zoroastrianism; however, Arab Conquest of Iran in 651 put an end to the Zoroastrianism and Sasanian Empire, turning the official religion of Iran to Islam. Ever since, different dynasties (i.e., Shahs) ruled in Iran (Yarshater 2013). The last Shah of Iran, Mohammad Reza Pahlavi (1919-1980), was overthrown by Islamic Revolution on February 11, 1979. After the Islamic Revolution of 1979, monarchy was abolished, Islamic rules were strengthened in the constitution, and the country was renamed to Islamic Republic of Iran. Families were strongly encouraged by social and political figures to produce more children to strengthen the Islamic Revolution's future. Therefore, fertility increased for several years (Erfani and McQuillan 2014). However, recent trends show that fertility in Iran is decreasing. The fertility rate in the Islamic republic of Iran fell from around 7.0 births per woman in the early 1980 s to 2.1 births per woman in 2000 (Abbasi-Shavazi and McDonald 2006).

Islamic values have been systematically encouraged since the Islamic Revolution of Iran in 1979. In mating contexts, specifically, premarital sex was considered "inappropriate." Establishing and maintaining families were encouraged through Islamic values after the Islamic Revolution (Hojat, Shariat, and Ansari 2015;
Khosrokhavar 2007; Tashakkori and Thompson 1988). Within such an environment, people in Iran had access to sex almost exclusively through marriage. Consanguineous marriage was also frequently arranged (Saadat, Ansari-Lari, and Farhud 2004) but not as appreciated as in Arabic countries (Harkness and Khaled 2014). Mahr was strongly introduced to marriage in Iran. Mahr is a mandatory amount of money or possessions paid or promised to be paid by the groom to the bride at the time of the marriage contract (see Mir-Hosseini 1993; Aghajanian and Thompson 2013). Mahr is originally an Islamic concept in family law and is, traditionally, paid in gold coins (rather than Rials). Usually, men with economic stability can afford to accept higher Mahrs.

Considering all these considerable changes in religiosity, socio-economic status (see Alnasrawi 1986), population size, women's access to higher education (see Shams 2016), and marriage patterns, surprisingly little is known about women's long-term mate preferences in Iran (for an exception see Atari and Jamali 2016). The long-term and short-term cultural changes in Iran provide opportunities to test evolutionary psychological hypotheses in human mating psychology. In addition, cultural correlates of women's long-term mate preferences have not been empirically examined in Iran.

We designed the current study to provide new findings on mating psychology of Iranian women. The present study can provide scholars with descriptive and inferential data on individual difference and cultural correlates of long-term mate preferences in Iran as a non-Western culture. Considering the body of literature, we made the following a priori hypotheses: (H1) Religiosity would be positively associated with preference for religiosity/ chastity (see Buss 1985); (H2) Socio-economic status would be positively associated with preference for status/resources (see Buss 1985; Khallad 2005); (H3) Self-perceived attractiveness would be positively associated with preference for status/resources (H3a), attractiveness/sexuality (H3b), kindness/dependability $(\mathrm{H} 3 \mathrm{c})$, and education/intelligence (H3d) (see Buss and Shackelford 2008); (H4) Self-rated intelligence would be positively associated with preference for education/ intelligence (see Stanik and Ellsworth 2010); (H5) Selfrated intelligence would be negatively associated with preference for status/resources (see Stanik and Ellsworth 2010); (H6) The desired Mahr would be positively associated with preference for status/resources (see Introduction); (H7) The desired number of children would be associated with preference for religiosity/chastity (see Atari and Jamali 2016); (H8) The desired number of children in the current sample is lower than that of Iranian women in 1980s as reported in Buss, Shackelford, and LeBlanc (2000). 


\section{Methods}

\section{Participants}

Participants were 536 single women who were recruited from university settings in Tehran, Iran. Participants ranged in age between 18 and $47(M=21.6, S D=3.78)$. In terms of educational qualification, 7 participants had an associate's degree, 327 participants had a bachelor's degree, 106 participants had a master's degree, and 96 participants had a doctorate degree. All participants identified themselves as Iranian and heterosexual.

\section{Measures}

Women's Mate Preferences We used the female-specific mate preference scale developed by Atari and Jamali (2016). This 26-item scale has shown good psychometric properties in Iranian context. All items are characteristics in a potential mate and are rated along a 4-point Likert-type scale ranging from 1 (Unimportant) to 4 (Very important). This measure consists of five subscales: kindness/dependability, status/resources, attractiveness/sexuality, religiosity/chastity, and education/intelligence. We averaged items of each subscale to reach a subscale score. In the current study, Cronbach's alpha coefficients were $.79, .82, .85, .70$, and .71 , respectively.

Religiosity The self-rating religiosity (SRR) is a single-item measure of religiosity (Abdel-Khalek 2007). Participants responded to this single-item measure on an 11-point scale $(0=$ indicating no religiosity to $10=$ indicating high level of religiosity). While single-item measures are limiting in terms of breadth, single-item measures of religiosity have been used in various samples (e.g., Swami et al. 2013) and cross-cultural studies (Abdel-Khalek and Lester 2010).

Self-Perceived Attractiveness We used a single-item measure of Self-Perceived Attractiveness (SPA) to assess participants' subjective perception of their physical attractiveness. We used the measure used by Kalantar-Hormozi, Jamali, and Atari (2016). Responses are in percentile format ranging from 0 (indicating minimum attractiveness) to 100 (indicating maximum attractiveness).

Self-Rated Intelligence We adapted a single-item measure of self-rated intelligence similar to the item assessing selfperceived attractiveness. Participants provided a subjective assessment of their general intelligence on a percentile format ranging from 0 (indicating minimum intelligence) to 100 (indicating maximum intelligence). According to the normal distribution of intelligence, a percentile of 50 would mean a subjective intelligence quotient (IQ) of 100 (Furnham 2001).
Marriage Arrangement Preferences Participants responded to a set of questions on marriage. Specifically, we asked the following questions: (1) "What age is appropriate for women to get married?" [minimum and maximum], (2) "What age is appropriate for men to get married?" [minimum and maximum], (3) "How do you prefer your future husband in terms of age difference?" [participants could select younger, the same age, or older], (4) "How much spousal age difference do you prefer?" [Minimum and maximum], and (5) "How many children would you like to have in the future?".

Demographic and Cultural Variables In addition to demographic details, we asked a number of culture-related questions. In the demographic section, we included age, marital status, sex, socio-economic status (on a 5-point Likert scale; see Leung and Xu 2013), and educational qualification. In the culture-specific section, we asked the following questions: (1) "Which arrangement do you prefer for marriage, arranged or modern?", (2) "Do you agree with the whole constitution of Mahr?", and (3) "How much would you ask for Mahr upon your marriage (in gold coins)?”.

\section{Procedure}

All participants were recruited from university settings in Tehran, Iran. Potential participants were approached and asked to take part in a psychological study regarding marriage attitudes in university students. Only single participants were included in the study as current relationships could potentially alter one's mate preferences. Participation was on a voluntary basis and participants were not remunerated.

\section{Data Analysis}

Means were created for self-report measures. We reported descriptive statistics (mean and standard deviation) for each variable. Bivariate correlations were used to test hypotheses 1 to 7 . We also used one-sample $t$ test, accompanied by effect size and $95 \%$ confidence interval for mean difference, to compare the desired number of children in this study with a previously published report (hypothesis 8 ). All analyses were conducted using SPSS 22.

\section{Results}

Descriptive statistics of the variables are presented in Table 1. Moreover, the median for Mahr was 120 gold coins $($ Min $=0$, Max $=4000$ ). As can be seen, women, on average, consider the interval between 22.6 and 29.4 years as a suitable age for women to get married. On the other hand, women, on average, 
Table 1 Descriptive statistics for study variables

\begin{tabular}{lllr}
\hline Variable & Range & $M$ & SD \\
\hline Min. age for women's marriage & $16-35$ & 22.6 & 2.54 \\
Max. age for women's marriage & $23-45$ & 29.4 & 3.56 \\
Min. age for men's marriage & $18-35$ & 26.3 & 2.41 \\
Max. age for men's marriage & $25-55$ & 33.6 & 4.06 \\
Min. spousal age difference & $0-10$ & 2.6 & 1.61 \\
Max. spousal age difference & $0-25$ & 6.8 & 2.75 \\
Desired number of children & $0-5$ & 2.16 & 1.00 \\
Socio-economic status & $1-5$ & 3.45 & 0.66 \\
Self-rated intelligence & $0-100$ & 63.2 & 19.92 \\
Self-perceived attractiveness & $0-100$ & 62.5 & 21.17 \\
Self-rating of religiosity & $0-10$ & 5.16 & 2.05 \\
\hline
\end{tabular}

consider the age period between 26.3 and 33.6 years a suitable age period for men to get married. On average, Iranian women in the present sample reported 2.6 to 6.8 years as preferred spousal age difference.

In response to the question regarding preferred arrangement for marriage, 435 participants ( $81.2 \%$ ) preferred modern ways without involvement of families. The rest of the sample $(18.8 \%)$ preferred arranged marriage. In response to the question regarding age difference, 497 participants $(92.7 \%)$ preferred older partners, 36 participants $(6.7 \%)$ preferred the same age, and 3 participants $(0.6 \%)$ preferred younger partners. In response to the question on Mahr, 441 participants (82.3\%) did not find Mahr as a useful arrangement in marriage.

Table 2 displays descriptive statistics of the dimensions of mate preferences as well as their correlations with other study variables. As indicated in Table 2, religiosity was positively associated with preference for religiosity/chastity and women's socio-economic status was also positively associated with preference for status/resources. Therefore, $\mathrm{H} 1$ and $\mathrm{H} 2$ are fully supported. In addition, religiosity was negatively associated with preference for attractiveness/sexuality $(p=.04)$ and status/resources $(p=.03)$. Socio-economic status was also positively associated with preference for attractiveness/ sexuality $(p<.01)$ and education/intelligence $(p=.01)$.
As displayed in Table 2, self-perceived attractiveness was positively associated with preference for status/resources $(p<.01)$, attractiveness/sexuality $(p<.01)$, and kindness/ dependability $(p=.01)$, supporting H3a, H3b, and H3c. The correlation coefficient between self-perceived attractiveness and preference for education/intelligence was positive $(r=.07)$, but only marginally significant $(p=.09)$. Therefore, H3d is partly supported.

In support of $\mathrm{H} 4$, self-rated intelligence was positively associated with preference for education/intelligence $(p<.01)$. Interestingly, while we predicted a negative association between self-rated intelligence and preference for status/ resources (see H5), a significant positive correlation emerged $(r=.16, p<.01)$. In addition, self-rated intelligence was positively associated with preference for attractiveness/sexuality $(p<.01)$.

As shown in Table 2, the desired Mahr was positively associated with preference for status/resources $(p=.01)$. As a result, H6 is supported. In addition, Mahr was negatively associated with kindness/dependability $(p<.01)$. The desired number of children was positively associated with preference for religiosity/chastity $(p<.01)$, which supported H6.

It can also be seen in Table 1 that young Iranian women desire 2.16 children $(S D=1.00)$. The desired number of children in the current sample was significantly smaller than that reported in Buss et al. (2000), $t=8.37, p<.01$. The magnitude of this difference was small to moderate (mean difference $=0.36,95 \% C I=0.28-0.45, d=.36$ ). Therefore, hypothesis 8 is supported.

\section{Discussion}

The present study aimed to provide new data from Iran as a non-Western setting that has been excluded from evolutionary psychological research, particularly mate preferences (Shackelford, Schmitt, and Buss 2005). We provided a set of descriptive data on long-term mate preferences with a relatively large sample of single Iranian women. Furthermore, we examined the associations between dimensions of mate
Table 2 The relationship between dimensions of mate preferences and other study variables

\begin{tabular}{llllllll}
\hline Variable & $M(\mathrm{SD})$ & $\mathrm{DNC}$ & $\mathrm{Mahr}$ & $\mathrm{SRI}$ & $\mathrm{SPA}$ & $\mathrm{SRR}$ & $\mathrm{SES}$ \\
\hline Kindness/dependability & $3.85(0.24)$ & .06 & $-.13^{* *}$ & .04 & $.11^{*}$ & .02 & .04 \\
Status/resources & $3.09(0.56)$ & -.08 & $.11^{*}$ & $.16^{* *}$ & $.18^{* *}$ & $-.09^{*}$ & $.16^{* *}$ \\
Attractiveness/sexuality & $2.80(0.66)$ & -.03 & .05 & $.20^{* *}$ & $.23^{* *}$ & $-.09^{*}$ & $.13^{* *}$ \\
Religiosity/chastity & $3.02(0.63)$ & $.25^{* *}$ & -.08 & -.02 & -.02 & $.52^{* *}$ & .02 \\
Education/intelligence & $3.21(0.64)$ & -.06 & .05 & $.13^{* *}$ & .07 & -.01 & $.11^{*}$ \\
\hline
\end{tabular}

$D N C$ desired number of children, $S R I$ self-rated intelligence, $S P A$ self-perceived attractiveness, $S R R$ self-rating of religiosity, SES socio-economic status

$* p<.05 * * p<.01$ 
preferences and a number of important variables including culture-specific factors (e.g., Mahr). Specifically, we tested a priori hypotheses on the relationships between mate preferences and cultural and individual difference correlates. The current findings may provide a basis for scholars who work in the area of mate preferences to build upon.

First, descriptive findings have important implications. Interestingly, a large proportion of the present sample did not approve of Mahr as a useful tool for in marriage. This is, particularly, interesting because Mahr is thought to be protecting women against unilateral divorce and the present sample was an all-female sample. Additionally, a large proportion of the women preferred modern ways to get married leaving out family involvement (i.e., arranged marriage). The present findings show that the majority of Iranian women would like to select their romantic partner themselves rather than follow their family choices. These findings show that young Iranian women are less strongly attached to old cultural standards compared to what previous studies reported (also see Simbar, Tehrani, and Hashemi 2005; Hojat, Shariat, and Ansari 2015). This is consistent with a recent study reporting that traditional shame and stigma attached to divorce are fading in Iranian culture (Aghajanian and Thompson 2013) and another recent study reporting high prevalence of premarital sex in young Iranian women (Honarvar et al. 2016).

In terms of preferred age difference between self and spouse, Buss (1989) reported that Iranian women preferred spouses 5.1 years older than themselves. Moreover, Samani and Ryan (2008) reported that single Iranian women preferred spouses 4.4 years older. In the current study, we asked minimum and maximum acceptable age difference between self and spouse. The average of the minimum age difference was 2.6 years and the average of the maximum age difference was 6.8 years.

The first hypothesis indicated that those women who scored higher on religiosity showed a higher desire for religiosity/chastity. This is in line with the notion of "birds of a feather flock together," i.e., people with similar interests tend to be found together (e.g., Chen et al. 2009). More religious women also showed less desire for attractiveness/sexuality and status/resources. Sexual openness may be a marker of weaker religious attitudes. Moreover, it is recommended in Islam to have simple non-luxury marriages with a small amount of Mahr (see Azahari and Ali 2015). This may account for the small-sized negative relationship between religiosity and preference for status/resources.

Some scholars (e.g., Wood and Eagly 2002) have provided evidence indicating that socio-cultural factors (e.g., socioeconomic status [SES] and trends) can account for sex differences in mate preferences (Bech-Sørensen and Pollet 2016). Eagly and Wood (1999) concluded that women with higher SES place less emphasis on mate's financial status. Some other studies have indicated an increase in preference for a potential mate's financial status with the elevation of women's SES (Wiederman and Allgeier 1992). Some other studies have found non-significant relationships or very small effects in this regard (e.g., Khallad 2005). The present data supported our second hypothesis, showing that women's SES was positively correlated with preference for status/resources. In addition, socio-economic status was positively associated with preferences for attractiveness/sexuality and intelligence/education. However, the magnitude of these relationships was small.

Self-perceived attractiveness may be considered an important index of self-perceived mate value in women (Fisher, Cox, Bennett, and Gavric 2008). Those who consider themselves attractive set higher standards for dimensions of kindness/dependability, attractiveness/sexuality, status/resources, and intelligence/education. These correlations are in line with the notion of "attractive women want it all," i.e., those women who consider themselves as attractive prefer more desirable traits in mate selection (Buss and Shackelford 2008). Of note, self-perceived attractiveness was not related to preference for religiosity/chastity in a potential mate.

Self-rated intelligence may be considered an index of selfperceived mate value (Fisher et al. 2008). The finding that women with higher self-rated intelligence prefer more intelligent and educated men (H4) is consistent with the similarity hypothesis (Buss 1985). In other words, women who think they are intelligent prefer more educated/intelligent partners. In the present study, based on Stanik and Ellsworth (2010), we hypothesized that women who perceive themselves as intelligent would set lower standards for their potential partner's social status and resources (H5). Stanik and Ellsworth (2010) found a negative correlation between intelligence and the desire for men with social status and resources. They argued that women with higher intelligence can build up a successful profession and provide for their potential offspring without financial aid of the male partner. However, opposite to our hypothesis 5 , we found a positive correlation between self-rated intelligence and desire for status/resources. Two explanations may account for this difference. First, Stanik and Ellsworth (2010) used objective intelligence tests while we used subjective ratings. Second, in Western societies, intelligence may serve as a reliable predictor of economic success and well-paid career (Kuncel, Hezlett, and Ones 2004; Strenze 2007). There is no empirical report to support the same hypothesis in contemporary Iran. In fact, some observations are not in favor of that hypothesis.

Those who wanted higher amount of Mahr scored higher on the dimension of status/resources and scored lower on the dimension of kindness/dependability. Predictably, those women who want to set higher amount of Mahr upon marriage prefer men who are financially more stable; therefore, the husband can afford to pay the Mahr. On the other hand, those who have high standards for kindness and dependability characteristics may actually count on their partner's good 
personality indicators (e.g., loyalty and dependability) instead of a legal assurance such as Mahr to provide paternal care for their potential offspring. In the first case scenario, the woman makes sure of her and her potential offspring's future comfort using a legal asset. In the second case, however, the woman makes sure that her mate is dependable and loyal enough to support and provide for her (potential) offspring.

According to the notion of modernization of Iran, especially in reproductive context, we hypothesized that women in contemporary Iran desire a smaller number of children compared with reports from 1980s (H8). Using archival data from 1980s including a small sample from Iran, Buss et al. (2000) reported that Iranian women desired 2.52 children on average; however, women in the current sample desired 2.16 children on average. Hypothesis 8 was statistically supported. In line with the notion of modernization of Iran, young women in the present sample desired a smaller number of children.

In sum, the present study provided descriptive data on marriage preferences of young Iranian women. Additionally, we tested hypotheses regarding the relationships between dimensions of women's long-term mate preferences and the desired number of children, Mahr, self-rated intelligence, selfperceived attractiveness, religiosity, and socio-economic status. Some limitations of the present study are worth noting. First, the present sample was drawn from university settings in Tehran and may not necessarily reflect attitudes of all Iranian women. It is recommended for future research to replicate the present findings in diverse samples in terms of education, socio-economic status, language, and subcultures. Second, we used a large number of single-item measures (e.g., selfrated intelligence, self-perceived attractiveness, and religiosity). It is recommended for future research to extend the present findings using psychometrically robust measures (e.g., for self-perceived attractiveness, see Sneade and Furnham 2016).

\section{References}

Abbasi-Shavazi, M., \& McDonald, P. (2006). Fertility decline in the Islamic Republic of Iran: 1972-2000. Asian Population Studies, 2, 217-237. doi:10.1080/17441730601073789.

Abdel-Khalek, A. M. (2007). Assessment of intrinsic religiosity with a single-item measure in a sample of Arab Muslims. Journal of Muslim Mental Health, 2, 211-215. doi:10.1080/15564900701614874.

Abdel-Khalek, A. M., \& Lester, D. (2010). Constructions of religiosity, subjective well-being, anxiety, and depression in two cultures: Kuwait and USA. International Journal of Social Psychiatry, 58, 138-145. doi:10.1177/0020764010387545.

Aghajanian, A., \& Thompson, V. (2013). Recent divorce trend in Iran. Journal of Divorce \& Remarriage, 54, 112-125. doi:10.1080 /10502556.2012.752687.

Alnasrawi, A. (1986). Economic consequences of the Iraq-Iran war. Third World Quarterly, 8, 869-895. doi:10.1080/01436598608419929.

Atari, M., \& Jamali, R. (2016). Dimensions of women's mate preferences: validation of a mate preference scale in Iran. Evolutionary
Psychology. doi:10.1177/1474704916651443. Advance Online Publication.

Azahari, R., \& Ali, H. M. (2015). Mahr as a form of economic security: a preliminary study. Arab Law Quarterly, 29, 296-305. doi:10.1163 /15730255-12341300.

Bech-Sørensen, J., \& Pollet, T. V. (2016). Sex differences in mate preferences: a replication study, 20 years later. Evolutionary Psychological Science, 1-6. doi: 10.1007/s40806-016-0048-6

Buss, D. M. (1985). Human mate selection: opposites are sometimes said to attract, but in fact we are likely to marry someone who is similar to us in almost every variable. American Scientist, 73, 47-51.

Buss, D. M. (1989). Sex differences in human mate preferences: evolutionary hypotheses tested in 37 cultures. Behavioral and Brain Sciences, 12, 1-14. doi:10.1017/s0140525x00023992.

Buss, D. M. (1994). The evolution of desire: strategies of human mating. New York: Basic Books.

Buss, D. M., \& Shackelford, T. K. (2008). Attractive women want it all: good genes, economic investment, parenting proclivities, and emotional commitment. Evolutionary Psychology, 6, 134-146. doi:10.1177/147470490800600116.

Buss, D. M., Shackelford, T. K., \& LeBlanc, G. J. (2000). Number of children desired and preferred spousal age difference: contextspecific mate preference patterns across 37 cultures. Evolution and Human Behavior, 21,323-331. doi:10.1016/s1090-5138(00)00048-9.

Chang, L., Wang, Y., Shackelford, T. K., \& Buss, D. M. (2011). Chinese mate preferences: cultural evolution and continuity across a quarter of a century. Personality and Individual Differences, 50, 678-683. doi:10.1016/j.paid.2010.12.016.

Chen, H., Luo, S., Yue, G., Xu, D., \& Zhaoyang, R. (2009). Do birds of a feather flock together in China? Personal Relationships, 16, 167186. doi:10.1111/j.1475-6811.2009.01217.x.

Clark, R. D., \& Hatfield, E. (1989). Gender differences in receptivity to sexual offers. Journal of Psychology and Human Sexuality, 2, 3955. doi:10.1300/j056v02n01 04.

Clutton-Brock, T. H. (1991). The evolution of parental care. Princeton, NJ: Princeton University Press.

Eagly, A. H., \& Wood, W. (1999). The origins of sex differences in human behavior: evolved dispositions versus social roles. American Psychologist, 54, 408-423. doi:10.1037/0003-066 X.54.6.408.

Erfani, A., \& McQuillan, K. (2014). The changing timing of births in Iran: an explanation of the rise and fall in fertility after the 1979 Islamic Revolution. Biodemography and Social Biology, 60, 6786. doi:10.1080/19485565.2014.899428.

Fisher, M., Cox, A., Bennett, S., \& Gavric, D. (2008). Components of self-perceived mate value. Journal of Social, Evolutionary, and Cultural Psychology, 2, 156-168. doi:10.1037/h0099347.

Frederick, D. A., Reynolds, T. A., \& Fisher, M. L. (2013). The importance of female choice: evolutionary perspectives on constraints, expressions, and variations in female mating strategies. In R. Chang, M. Fisher, \& J. Garcia (Eds.), Evolution's empress: Darwinian perspectives on the nature of women (pp. 304-329). Oxford, UK: Oxford Press.

Furnham, A. (2001). Self-estimates of intelligence: culture and gender difference in self and other estimates of both general $(\mathrm{g})$ and multiple intelligences. Personality and Individual Differences, 31, 13811405. doi:10.1016/s0191-8869(00)00232-4.

Harkness, G., \& Khaled, R. (2014). Modern traditionalism: consanguineous marriage in Qatar. Journal of Marriage and Family, 76, 587603. doi:10.1111/jomf.12106.

Hojat, M., Shariat, S. V., \& Ansari, S. (2015). Iranian college students' attitudes toward premarital sex, marriage, and family before and after the Islamic Revolution. International Journal of Sexual Health, 27, 224-234. doi:10.1080/19317611.2014.957794.

Honarvar, B., Salehi, F., Barfi, R., Asadi, Z., Honarvar, H., Odoomi, N., ... \& Lankarani, K. B. (2016). Attitudes toward and experience of 
singles with premarital sex: a population-based study in Shiraz, Southern Iran. Archives of Sexual Behavior, 45, 395-402. doi: 10.1007/s10508-015-0577-2

Huyse, P. (1998). Iranian history in pre-Islamic times. Iranian Studies, 31, 417-430. doi:10.1080/00210869808701922.

Kalantar-Hormozi, A., Jamali, R., \& Atari, M. (2016). Interest in cosmetic surgery among Iranian women: the role of self-esteem, narcissism, and self-perceived attractiveness. European Journal of Plastic Surgery, 1-6. doi: 10.1007/s00238-016-1185-7.

Kamble, S., Shackelford, T. K., Pham, M., \& Buss, D. M. (2014). Indian mate preferences: continuity, sex differences, and cultural change across a quarter of a century. Personality and Individual Differences, 70, 150-155. doi:10.1016/j.paid.2014.06.024.

Khallad, Y. (2005). Mate selection in Jordan: effects of sex, socioeconomic status, and culture. Journal of Social and Personal Relationships, 22, 155-168. doi:10.1177/0265407505050940.

Khosrokhavar, F. (2007). The new religiosity in Iran. Social Compass, 54 , 453-463. doi:10.1177/0037768607080842.

Kuncel, N. R., Hezlett, S. A., \& Ones, D. S. (2004). Academic performance, career potential, creativity, and job performance: can one construct predict them all? Journal of Personality and Social Psychology, 86, 148-161. doi:10.1037/0022-3514.86.1.148.

Leung, S. O., \& Xu, M. L. (2013). Single-item measures for subjective academic performance, self-esteem, and socioeconomic status. Journal of Social Service Research, 39, 511-520. doi:10.1080 /01488376.2013.794757.

Mir-Hosseini, Z. (1993). Women, marriage and the law in postrevolutionary Iran. In Women in the Middle East (pp. 59-84). Palgrave Macmillan UK. doi: 10.1007/978-1-349-22588-0_3

Saadat, M., Ansari-Lari, M., \& Farhud, D. D. (2004). Consanguineous marriage in Iran. Annals of Human Biology, 31, 263-269. doi:10.1080/03014460310001652211.

Samani, S., \& Ryan, B. A. (2008). Spouse selection: important criteria and age preferences of an Iranian sample. Psychological Reports, 103, 535-544. doi:10.2466/pr0.103.2.535-544.

Schmitt, D. P. (2005). Sociosexuality from Argentina to Zimbabwe: a 48nation study of sex, culture, and strategies of human mating. Behavioral and Brain Sciences, 28, 247-275. doi:10.1017 /s0140525x05000051.

Schmitt, D. P., \& Jonason, P. K. (2014). Attachment and sexual permissiveness exploring differential associations across sexes, cultures, and facets of short-term mating. Journal of Cross-Cultural Psychology, 46, 119-133. doi:10.1177/0022022114551052.

Schmitt, D. P., \& Fuller, R. C. (2015). On the varieties of sexual experience: cross-cultural links between religiosity and human mating strategies. Psychology of Religion and Spirituality, 7, 314-326. doi: $10.1037 /$ rel0000036.

Shackelford, T. K., Schmitt, D. P., \& Buss, D. M. (2005). Universal dimensions of human mate preferences. Personality and
Individual Differences, 39, 447-458. doi:10.1016/j. paid.2005.01.023.

Simbar, M., Tehrani, F. R., \& Hashemi, Z. (2005). Reproductive health knowledge, attitudes, and practice of Iranian college students. Eastern Mediterranean Health Journal, 11, 888-897.

Shams, A. (2016). Revolutionary religiosity and women's access to higher education in the Islamic Republic of Iran. Journal of Middle East Women's Studies, 12, 126-138. doi:10.1215 /15525864-3422633.

Simpson, J. A., \& Gangestad, S. W. (1991). Individual differences in sociosexuality: evidence for convergent and discriminant validity. Journal of Personality and Social Psychology, 60, 870-883. doi:10.1037/0022-3514.60.6.870.

Sneade, M., \& Furnham, A. (2016). Hand grip strength and selfperceptions of physical attractiveness and psychological well-being. Evolutionary Psychological Science, 1-6. doi: 10.1007/s40806016-0042-z

Souza, A. L., Conroy-Beam, D., \& Buss, D. M. (2016). Mate preferences in Brazil: evolved desires and cultural evolution over three decades. Personality and Individual Differences, 95, 45-49. doi:10.1016/j. paid.2016.01.053.

Stanik, C. E., \& Ellsworth, P. C. (2010). Who cares about marrying a rich man? Intelligence and variation in women's mate preferences. Human Nature, 21, 203-217. doi:10.1007/s12110-010-9089-x.

Strenze, T. (2007). Intelligence and socioeconomic success: a metaanalytic review of longitudinal research. Intelligence, 35, 401-426. doi:10.1016/j.intell.2006.09.004.

Swami, V., Malpass, F., Havard, D., Benford, K., Costescu, A., Sofitiki, A., \& Taylor, D. (2013). Metalheads: the influence of personality and individual differences on preference for heavy metal. Psychology of Aesthetics, Creativity, and the Arts, 7, 377-383. doi:10.1037/a0034493.

Tashakkori, A., \& Thompson, V. D. (1988). Cultural change and attitude change: an assessment of postrevolutionary marriage and family attitudes in Iran. Population Research and Policy Review, 7, 3-27. doi:10.1007/bf00241760.

Trivers, R. (1972). Parental investment and sexual selection. In B. Campbell (Ed.), Sexual selection and the descent of man, 18711971 (pp. 136-179). Chicago: Aldine.

Wiederman, M. W., \& Allgeier, E. R. (1992). Gender differences in mate selection criteria: sociobiological or socioeconomic explanation? Ethology and Sociobiology, 13, 115-124. doi:10.1016/0162-3095 (92)90021-u.

Wood, W., \& Eagly, A. H. (2002). A cross-cultural analysis of the behavior of women and men: implications for the origins of sex differences. Psychological Bulletin, 128, 699-727. doi:10.1037/00332909.128.5.699.

Yarshater, E. (2013). The Iranians: their cultural heritage and its transformation. Iranian Studies, 46, 311-314. doi:10.1080 /00210862.2013.767108. 